\title{
Preferential Adsorption of Heavy Metals on Activated Carbon
}

\author{
V. Bhole, ${ }^{\text {a* }}$ D. S. Ramteke ${ }^{\mathrm{b}}$ \\ ${ }^{a}$ Dept. of Community Health Administration, National Institute of Health \& Family Welfare, New Mehrauli \\ Road, Munirka, New Delhi-110067 and ${ }^{b}$ EIRA Division, National Environmental Engineering Research Institute, \\ NehruÂ Marg, Nagpur-440020
}

\begin{abstract}
The removal of heavy metals in single, two and three-component system through adsorption was studied and found instant removal at the initial concentration of the adsorbate. Adsorption of metals by activated carbon has been found to be dependent on $\mathrm{pH}$, activated carbon dose and initial metal concentration, the type of activated carbon, its porosity and surface area. The Freundlich isotherms was used to fit the experimental data and to find out the adsorption parameters. The overall preferential adsorption pattern in multicomponent system of heavy metals was observed to be as $\mathrm{cd}>\mathrm{pb}>\mathrm{cr}$. Generally in wastewater treatment system heavy metals are removed through adsorption in tertiary treatment. So this trend will be useful in removing maximum percentage of heavy metals preferably in multicomponent system.
\end{abstract}

Key Words : Heavy metals, Adsorption, Single component system, Multicomponent system.

\section{Introduction}

Industrial activity and metallurgy have caused excessive heavy metal contamination of the environment by directly introducing heavy metals in to the atmosphere, waterways and soil. Without diminishing the role of other pollutants, the traces of toxic metals were considered in the investigation by virtue of their extremely high toxicities to all living forms including humans and the environment. All the trace elements follow the following trend: undersupply leads deficiency, optimum supply helps in healthy growth and oversupply leads to toxicity and even eventual death. The individual metal has specific effect but most of them exert biological effects through combination with sulphydryl groups. They are carcinogenic, mutagenic and teratogenic (Dara 1995,). From the reported limits for various heavy metals, it is clear that industrial effluent containing toxic heavy metals needs to be treated. The techniques employed for heavy metal removal include precipitation, ion exchange, adsorption, cementation, evaporation, reverse osmosis, electrolysis and electrodialysis. All the above processes have one or the other disadvantages like in precipitation consequent post treatment of effluent is needed to bring down the $\mathrm{pH}$ to permissible limits, cementation has major disadvantage of optimization and thermodynamic limitations, evaporation consumes large amount of energy, reverse osmosis has narrow acceptable temperature range, hence the process of adsorption was taken under investigation. It is highly efficient, low cost and it can remove inorganic, pesticides and carbamate insecticides from wastewater. Abundant natural materials have been suggested as potential adsorbents for heavy metals (Morel et al. 2003). Numerous chemical groups have been suggested to contribute adsorptive metal binding such as carboxyl, hydroxyl, carbonyl and sulphydryl. The role that any given group plays depends on their chemical state, binding strength (Nagel et al . 1995). Adsorption is totally dependent on the type of activated carbon, its porosity and surface area. Most importants are the surface functional groups. Hence there are chances for the preferential adsorption of heavy metals on to the activated carbon. In view of this a study has been carried out by taking the combination of heavy metals to infer the preferential adsorption of heavy metals on activated carbon for adsorption of heavy metals (Cadmium, Chromium and Lead) through single component system and multicomponent system that is metals in combination and their adsorption onto activated carbon.

\footnotetext{
* Corresponding author: E-mail: vaishali_1974@rediffmail.com
} 
In the adsorption kinetics, the effect of initial metal concentration, carbon dose, $\mathrm{pH}$ have been analysed. A range of equilibrium adsorption isotherm were obtained to quantitatively describe metal uptake.

\section{Chemical and Reagents}

The commercially available activated carbon was used. All the glasswares used in the study were of corning and Borosil make. Prior to use, the glasswares were soaked in nitric acid $(10 \%)$ solution for $24 \mathrm{hrs}$, then washed with tap water and further rinsed with double distilled water. All glasswares were again rinsed with double distilled water prior to use. All chemicals, reagents ad solvents used in the present study were of Analar/AR/ guaranteed reagent grade.The reagents required for chemical analysis of water extract were prepared as per standard method.Stock solution of (1000 ppm) of cadmium, lead, and chromium were prepared using cadmium sulphate, lead nitrate and potassium chromate respectively. These stock solutions were further used to prepare dilute solution of desired concentration for use in the experiment.

\section{Instruments}

Rectangular shaking machine was used to run the experiment for desired time. $\mathrm{pH}$ meter was calibrated with $\mathrm{pH}$ buffers 4.0 and 9.2. The surface functional groups of activated carbon were determined by infrared spectrophotometer. Silica crucible having $25 \mathrm{ml}$ capacity was used for the estimation of ash and moisture. Volatile matter crucible Cylindrical made up of silica having $3.0 \mathrm{~cm}$ height, $1.0 \mathrm{~cm}$ external diameter, $0.9 \mathrm{~cm}$ internal diameter was used. Analysis of heavy metals was carried out with the AAS using air acetylene flame as per standard methods (Standard methods , 1995).

\section{The physico- chemical and adsorption study}

The physical characteristics of activated carbon were estimated in terms of particle size, apparent density, surface area and surface functional groups. For surface functional groups the commercial activated carbon was processed and palletized by the addition of potassium bromide and subjected to Infra Red spectrophotometer. From the peak threshold recorded by the recorder in terms of $\mathrm{cm}^{-1}$, different functional groups were identified.

Table I: Physical characteristics of activated carbon

\begin{tabular}{c|l|l}
\hline S. No. & Parameter & Value \\
\hline 1 & Particle size & $.55-$ \\
& $(\mathrm{mm})$ & 0.7 \\
2 & Bulk desity $\left(\mathrm{gm} / \mathrm{cm}^{3}\right)$ & 0.44 \\
3 & Suface area $\left(\mathrm{m}^{2} / \mathrm{g}\right)$ & 1100 \\
\hline
\end{tabular}

Table II: Proximate Analysis of activated carbon

\begin{tabular}{c|l|l}
\hline S. No. & Parameter & Value \\
\hline 1 & Moisture & 7.7 \\
2 & Ash & 1.0 \\
3 & Volatile Matter & 10.5 \\
4 & Fixed carbon & 80.8 \\
\hline
\end{tabular}

Table III: Asorption characteristics of activated carbon

\begin{tabular}{c|l|l}
\hline S. No. & Parameter & Value \\
\hline 1 & Parameter Value & 14 \\
2 & lodine value & 1000 \\
3 & Methylene Number & 384 \\
\hline
\end{tabular}

The Physical characteristics of the activated carbon are studied (Table I). The proximate analysis (Table II) and adsorptive characteristics (Table III) were studied. Chemical properties of activated carbon are studied from chemical analysis (Table IV) of water extract.

1. Moisture was determined by heating $1 \mathrm{gm}$ of activated carbon in a dried, clean silica crucible in an oven at $100^{\circ} \mathrm{C}$ to a constant weight. The difference in weight was calculated and expressed in percentage.

2. Ash was determined by heating 1 gm of activated carbon in a dried silica crucible at $800^{\circ} \mathrm{C}$ for one hour and weighed. The difference in weight was calculated and expressed in percentage.

3. Volatile matter was determined by heating 1 gm of activated carbon in volatile matter crucible in absence of air at $900^{\circ} \mathrm{C}$ for seven minutes and weighed. The difference in weight was calculated and expressed in percentage. 
4. Chemical characteristics of water extract- 1 gm of activated carbon was taken in $100 \mathrm{ml}$ distilled water in $250 \mathrm{ml}$ beaker and agitated for overnight. It was filtered with whatman no. 41 filter paper. Suitable aliquotes were taken for the estimation of $\mathrm{pH}$, alkalinity, chlorides, hardness, nitrates, phosphates (ortho), Sulphates sodium, potassium and heavy metals as per standard methods. The values obtained are shown in Table IV.

5. Adsorptive properties of activated carbon are determined in terms of phenol value, iodine number and methylene blue number.

Table IV: Chemical characteristics of Activated carbon

\begin{tabular}{c|l|c|c}
\hline S. No. & Parameter & Unit & Concentration \\
\hline 1 & $\mathrm{pH}$ & - & 7.0 \\
2 & Alkalinity $\left(\mathrm{CaCo}_{3}\right)$ & $\mathrm{Mg} / 1$ & 19.0 \\
3 & Chlorides & $\mathrm{Mg} / 1$ & 12.76 \\
4 & Hardness & $\mathrm{Mg} / 1$ & $\mathrm{ND}$ \\
5 & Nitrate & $\mathrm{Mg} / 1$ & 8.75 \\
6 & Phosphate(ortho) & $\mathrm{Mg} / 1$ & 0.075 \\
7 & Sulphate & $\mathrm{Mg} / 1$ & 22.5 \\
8 & Potassium & $\mathrm{Mg} / 1$ & 4.8 \\
9 & Chromium & $\mathrm{Mg} / 1$ & 9.0 \\
10 & Cadmium & $\mathrm{Mg} / 1$ & 0.03 \\
11 & Copper & $\mathrm{Mg} / 1$ & 0.022 \\
12 & Lead & $\mathrm{Mg} / 1$ & $\mathrm{ND}$ \\
13 & Manganese & $\mathrm{Mg} / 1$ & $\mathrm{ND}$ \\
14 & Iron & $\mathrm{Mg} / 1$ & $\mathrm{ND}$ \\
15 & Zinc & $\mathrm{Mg} / 1$ & $\mathrm{ND}$ \\
\hline
\end{tabular}

\section{Material and Method}

\section{Determination of optimum pH}

$10 \mathrm{mg} / \mathrm{l}$ solution of chromium, cadmium and lead was prepared from stock solution. $50 \mathrm{ml}$ each of the solution was taken in $300 \mathrm{ml}$ BOD bottles. The $\mathrm{pH}$ was adjusted to 2,3,4,5,6,7,8, with $0.1 \mathrm{HNO}_{3}$ and $0.1 \mathrm{~N} \mathrm{NaOH}$. Desired amount of activated carbon was weighed and added to each bottle. The solution was agitated for specified time (30 min) removed and filtered with whatman no. 40 filter paper. Residual metal concentration was estimated with atomic absorption spectrophotometer. The optimum $\mathrm{pH}$ for maxi- mum metal absorption was then selected and utilized for further studies. (Figure 1)

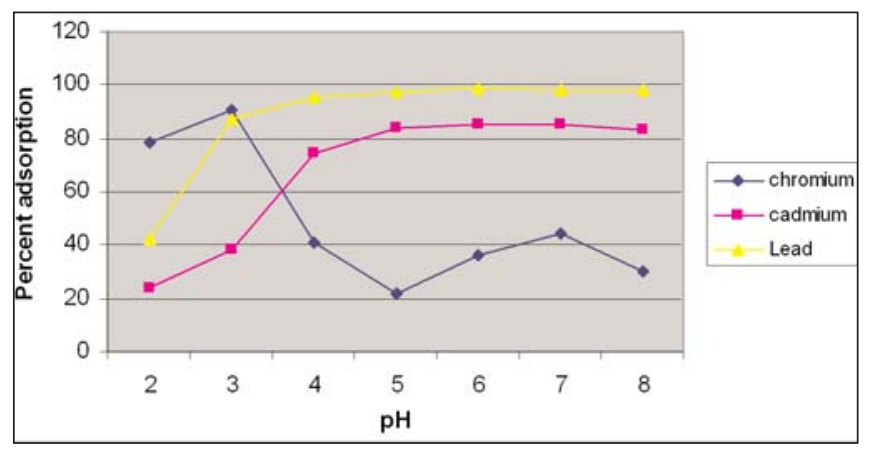

Fig. 1: Optimization of $\mathrm{pH}$ for the Adsorption of chromium, cadmium \& Lead on to Activated carbon

\section{Determination of Optimum Dose}

$50 \mathrm{ml}$ of $10 \mathrm{mg} / \mathrm{L}$ solution of chromium, cadmium and lead was taken in $300 \mathrm{ml}$ BOD bottles. Optimum $\mathrm{pH}$ was adjusted for each metal solution $(\mathrm{Cr}=3, \mathrm{Cd}=7, \mathrm{~Pb}=6)$ and various doses of activated carbon ranging from $400-4000 \mathrm{mg} / \mathrm{L}$ were added. The solution was agitated for desired contact time, filtered and filtrate was analysed for the individual metal for residual concentration using atomic absorption spectrophotometer. (Figure 2).

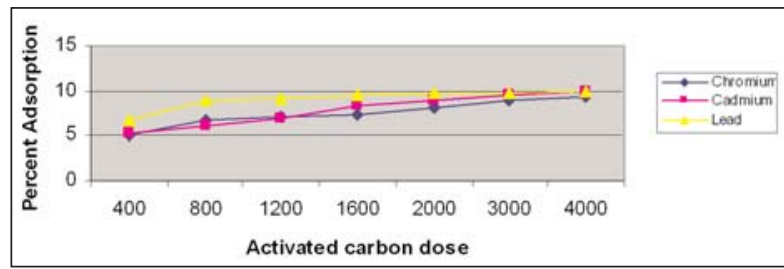

Fig. 2: Effect of Carbon dose on Adsorption of chromium, cadmium\& Lead on Activated carbon

\section{Single component system}

$100 \mathrm{ml}$ solution of each containing $5 \mathrm{mg} / \mathrm{l}$ of chromium, cadmium and lead were adjusted to optimum $\mathrm{pH}(\mathrm{Cr}=3, \mathrm{Cd}=7$, $\mathrm{Pb}=6$ ) and optimum dose ( $\mathrm{Cr}-92.4, \mathrm{Cd}-99, \mathrm{~Pb}-99.1)$ was adjusted for desired contact time, filtered and filterate was analysed for the individual metal for residual concentration using atomic absorption spectrophotometer. 


\section{Multicomponent system}

\section{Two component system}

$50 \mathrm{ml}$ solution each containing $5 \mathrm{mg} / \mathrm{L}$ of chromium, cadmium and lead were adjusted to $\mathrm{pH}=7$ with $0.1 \mathrm{~N} \mathrm{HNO}_{3}$ and $0.1 \mathrm{~N} \mathrm{NaOH}$ different combinations of solutions viz. cadmium + chromium, cadmium + lead and lead + chromium were prepared and taken into $300 \mathrm{ml}$ BOD bottles. Different doses of activated carbon i.e. 50-500 mg/L were added and shaken for 30 minutes. These solutions were filtered and residual concentrations of individual metals were estimated from filtrate with atomic absorption spectrophotometer.

\section{Three Component Systems}

$33.3 \mathrm{ml}$ solution each containing $3.34 \mathrm{mg} / \mathrm{L}$ of chromium + cadmium + lead were adjusted to $\mathrm{pH}=7$ with $0.1 \mathrm{NHNO}_{3}$ and $0.1 \mathrm{~N} \mathrm{NaOH}$, These solutions were taken in $300 \mathrm{ml} \mathrm{BOD}$ bottles and different doses of activated carbon i.e. 50-500 $\mathrm{mg} / \mathrm{L}$ were added and shaken for 30 minutes. These solutions were filtered and through filtrate, residual concentration of each metal was estimated through atomic absorption spectrophotometer.

\section{Results and Discussions}

The removal of heavy metals in single, two, three-component system through adsorption was studied and found instant removal at the initial concentration of the adsorbate. Adsorption of metals by activated carbon has been found to be dependent on $\mathrm{pH}$, activated carbon dose and initial metal concentration. Most of the metals are adsorbed in acidic $\mathrm{pH}$ range by activated carbon [Dubinin . 1966]. The adsorption edge for chromium is found to be 2-3, for cadmium 2-7 and for lead 2-6. No adsorption of chromium occurred below pH-2 and above pH-8. [Sorg et al 1980]. Very low removal of chromium in reported in the $\mathrm{pH}$ of range 6.8-8.3 (Figure 1). From the results it is observed that with an initial concentration of $10 \mathrm{mg} / \mathrm{L}$ chromium, cadmium and lead, the maximum adsorption was found to be $92.4,99.00$ and $99.1 \%$ respectively at a dose of $4000 \mathrm{mg} / 1$ (Figure -2). The results also show that there is increase in adsorption with increase in doses of activated carbon. In single component system, linear adsorption isotherm was observed for cadmium as com- pared to chromium and lead indicating uniform adsorption throughout the system ( Figure 3-5). In two component system the pattern of adsorption for lead and chromium werefound to be similar, for chromium and cadmium, linear adsorption were found for cadmium while more and linear

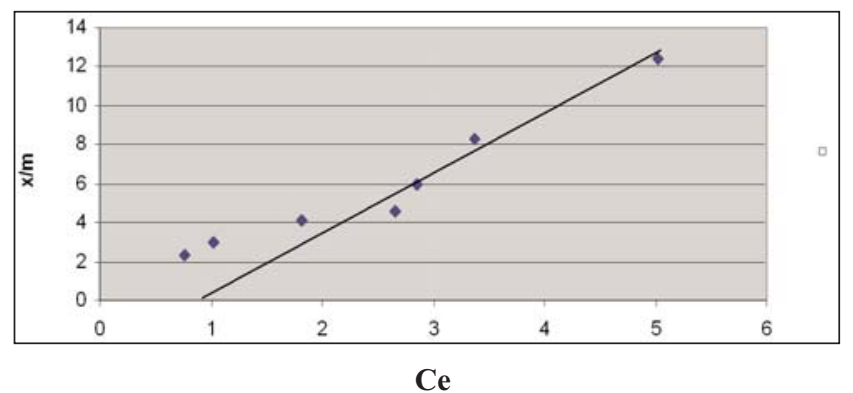

Fig. 3: Adsorption Isotherm Of Chromium

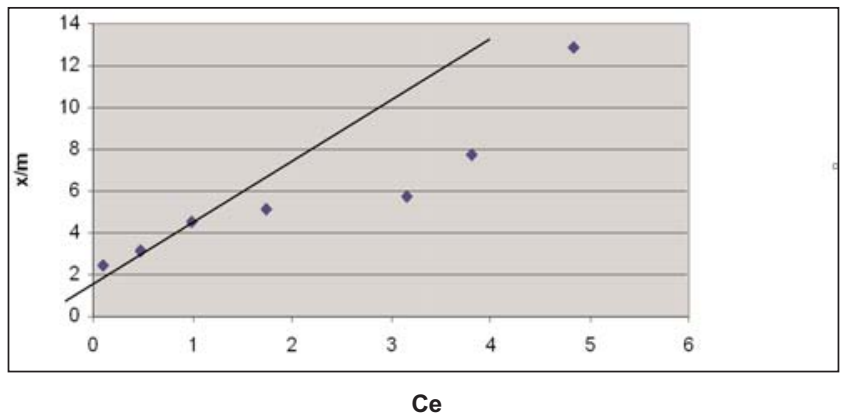

Fig. 4: Adsorption Isotherm of Cadmium

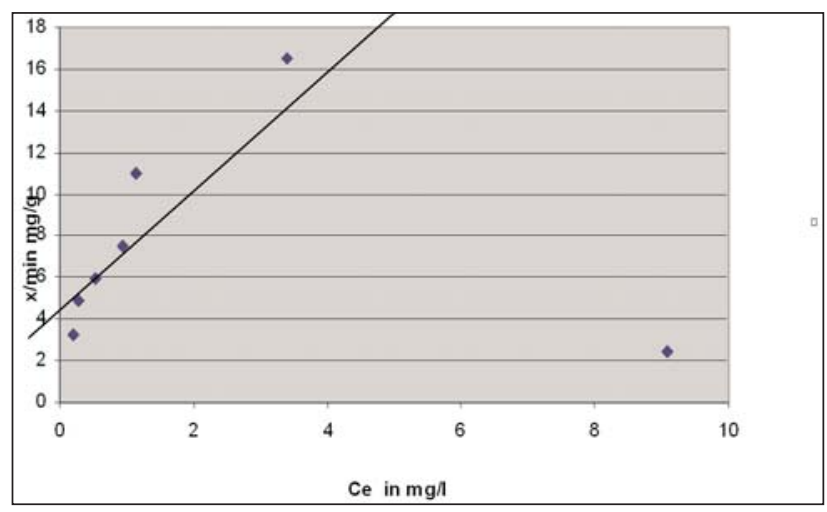

Fig. 5: Adsorption Isotherm Of Lead

adsorption was found in both the case of cadmium and lead in combination( Figure 6-11). 


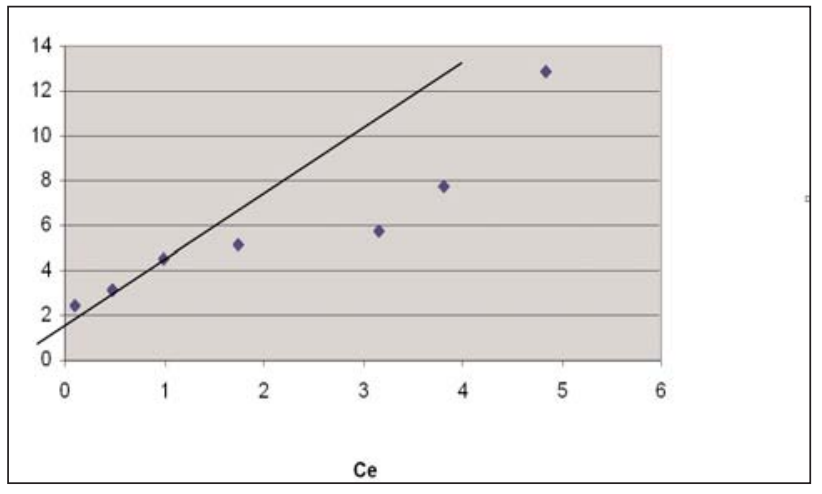

Fig. 6: Adsorption Isotherm of Lead In Presence of Cadmium

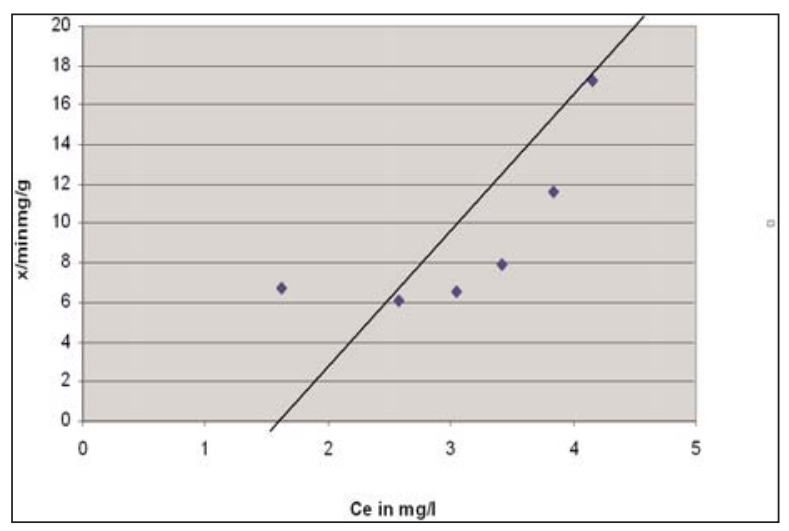

Fig.7: Adsorption Isotherm of Chromium in Presence of Lead

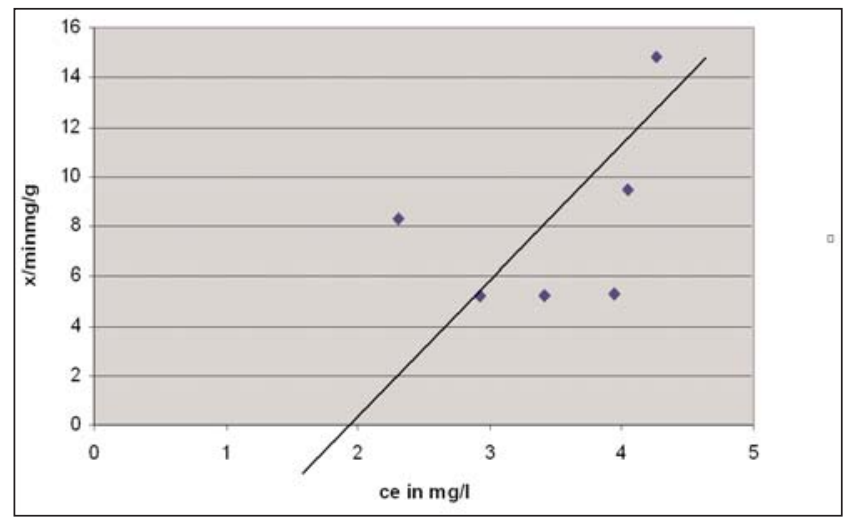

Fig. 8: Adsorption Isotherm of Chromium In Presence of Cadmium

In three component system linear adsorption pattern was observed for cadmium in presence of chromium and lead, while similar adsorption pattern was observed for chromium in presence of cadmium and lead and lead in presence of cadmium and chromium (Figure 12-14). The adsorption

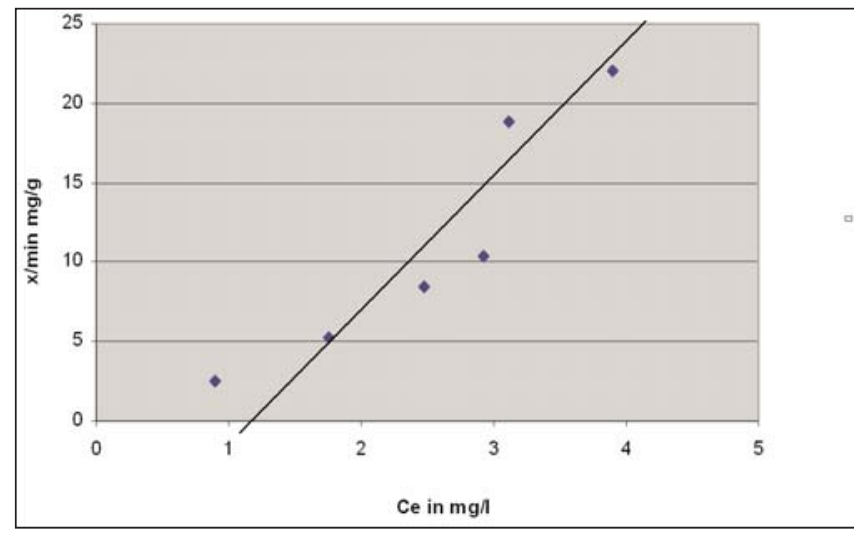

Fig. 9: Adsorption Isotherm of Cadmium In Presence of Lead

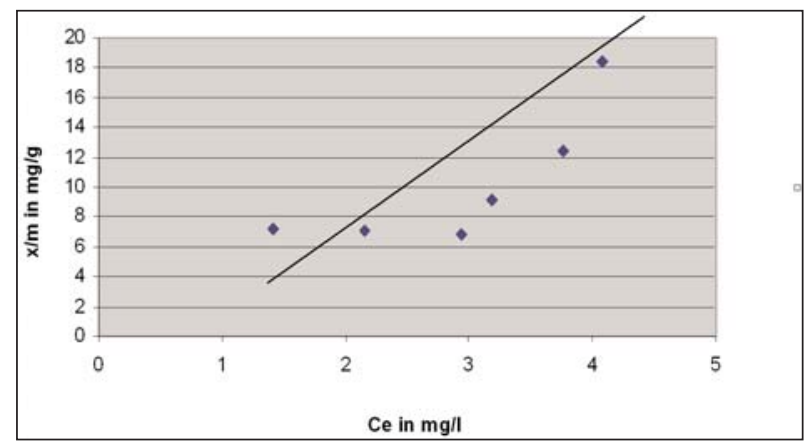

Fig. 10: Adsorption Isotherm of Lead in Presence of Chromium

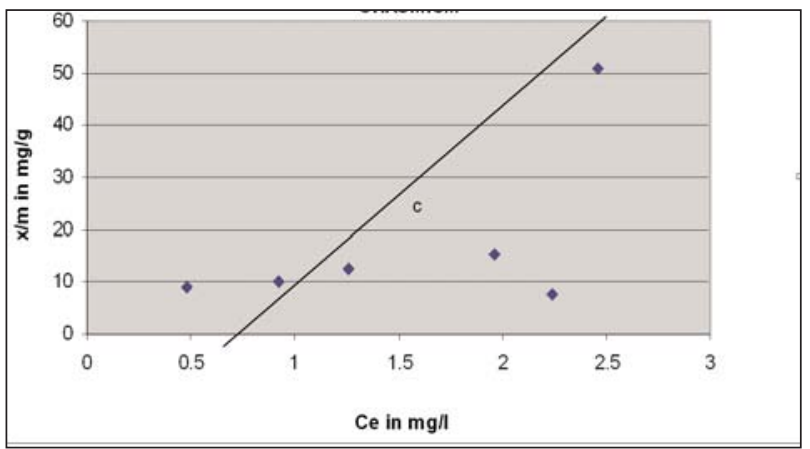

Fig. 11: Adsorption Isotherm of Cadmium in Presence of Chromium

mechanism can be explained as follows Adsorption is a surface phenomenon. Several types of isothermal adsorption 


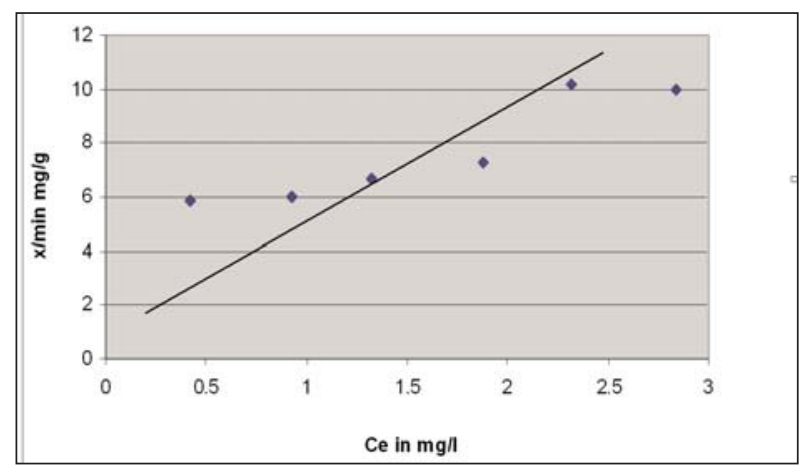

Fig. 12: Adsorption Isotherm Of Chromium In Presence Of Lead \& Cadmium

relations may occur. The most common being the system in which adsorption from solution layer of adsorbate molecules on the surface of the adsorbent. There are three types of adsorption isotherms known based on their individual equations i.e. Langmuir, Freundlich and BET. All these adsorp-

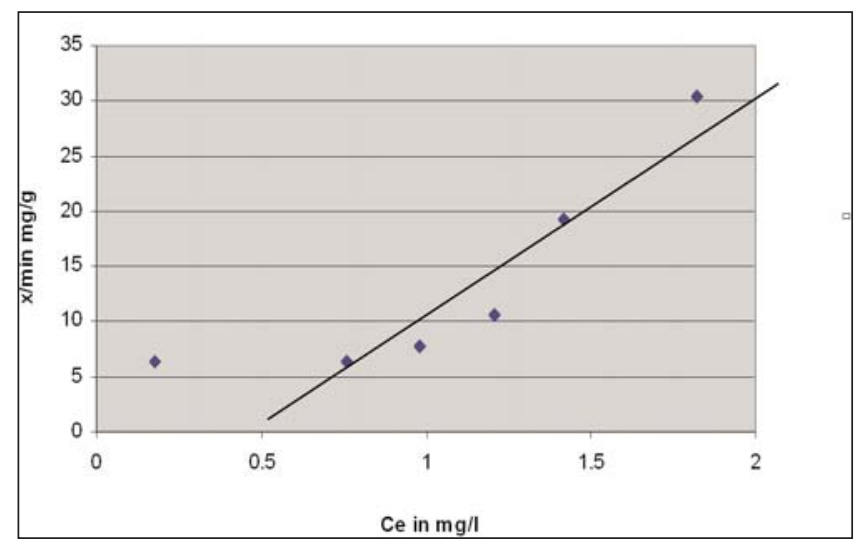

Fig. 13: Adsorption Isotherm Of Cadmium In Presence Of Lead \& Chromium

tion isotherm models have their significance. For the present study only Freundlich model was used. The data obtained for the system was fitted to the equation and isotherm was obtained. The Freundlich adsorption isotherms are shown in graph (Figure 13-14)

Adsorption is totally dependent on the type of carbon, surface area, surface functional groups, adsorbate concentration and the $\mathrm{pH}$ of the adsorbate [[Dubinin. 1966]]. From the IR studies the surface of the activated carbon displays $\underline{\mathrm{C}} \mathrm{OH}^{-}$ and $\mathrm{CO}^{-}$surface hydroxyl groups. For metals its surface complex formation reaction can be explained by

$$
\begin{array}{ll}
2(\mathrm{C} \mathrm{OH})+\mathrm{M}^{2+} & \left(\mathrm{CO}^{-}\right) 2 \mathrm{M}^{2+}+2 \mathrm{H}^{+} \ldots \ldots . .1 \\
2\left(\underline{\mathrm{CO}^{-}}\right)+\mathrm{M}^{2+} & \left(\underline{\mathrm{CO}^{-}}\right) 2 \mathrm{M}^{2+} \ldots \ldots . .1 \mathrm{a} \\
2(\underline{\mathrm{C}} \mathrm{OH})+\mathrm{MOH}^{+} & \left(\mathrm{CO}^{-}\right) 2 \mathrm{MOH}^{+}+2 \mathrm{H}^{+} \ldots .2 \\
2\left(\underline{\mathrm{CO}^{-}}\right)+\mathrm{MOH}^{+} & \left(\underline{\mathrm{CO}^{-}}\right) 2 \mathrm{MOH}^{+} \ldots \ldots \ldots \ldots . .2 \mathrm{a}
\end{array}
$$

Equations 1 or 1a and 2 or $2 \mathrm{a}$ are mutually dependent and equations $1 \& 2$ represent better reaction mechanisms than

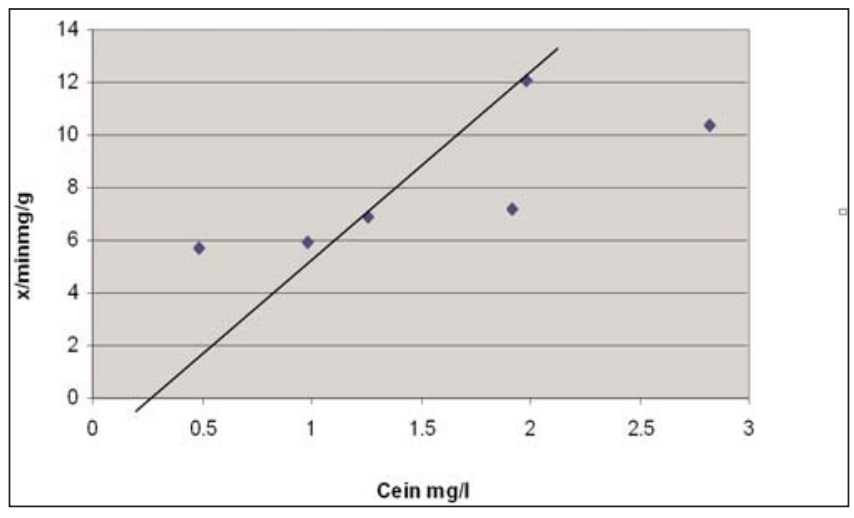

Fig. 14: Adsorption Isotherm Of Lead In Presence Of Chromium \& Cadmium

$1 \mathrm{a}$ and $2 \mathrm{a}$. The release of hydrated protons changes $\mathrm{pH}$ of the solution and thereby affect the solubility of the ingredients present in the activated carbon. Depending on the $\mathrm{pH}$, certain inorganic species known as polymeric species are also produced which have certain adsorption properties (Joesten et al.1974) .

Another mechanism could be explained in terms of the chemical bonding [Joesten et al .1964]. There are two major chemical bonding responsible for adsorption of heavy metals on the activated carbon. Surface covalent bonding and hydrogen bonding. The covalent bonding forms the outer surface complexes and hydrogen bonding forms inner surface complexes which are mainly related to the available surface oxygen on the activated carbon. The availability of surface oxygen in a particular type of activated carbon depends on the type of activation and temperature of activa- 
tion[Baes et al .1976]. Activated carbon are prepared physically and heated at 700.C. More surface oxygen is available at this temperature on the surface for chemical adsorption [Puri et al .1965].

Another mechanism could be explained on the basis of the surface functional groups. IR study had shown that the commercial activated carbon had carboxylic group, phenolic group, carbonyl group, lactone group, carboxylic acid unhydrite group and cyclic peroxide group. The role that any given group plays depends on factors such as the number of sites on the biosorbent, their accessibility and chemical state and the affinity between site and metal (binding strength) [Davis et al.2003] Cadmium is adsorbed more on activated carbon at $\mathrm{pH}-7$, chromium at $\mathrm{pH}-3$ and lead at $\mathrm{pH}$ -6 . When different combinations are used and adsorption is carried out at $\mathrm{pH}-7$, first the cadmium is adsorbed because of the favourable $\mathrm{pH}$ as it is hydrolysed first and form complex with the surface oxygenated groups on activated carbon and chemisorption occurs at the surface of the carbon releasing protons which reduce the $\mathrm{pH}$ of the solution which bring the favourable $\mathrm{pH}$ to lead and adsorption of lead is observed. However not much groups are left for the complexation of the lead with surface oxygenated groups on the activated carbon so less adsorption of chromium could be explained on the basis of $\mathrm{pH}$ only. Since in single component system maximum adsorption is occurred at $\mathrm{pH}-3$ whreas in combination of metal studies, $\mathrm{pH}$ is adjusted to 7 , so maximum chromium(VI) is converted into chromium (III) at this $\mathrm{pH}$ and this is the reason of less adsorption of chromium.

\section{Conclusion}

The removal of heavy metals in single, two and three component system through adsorption is studied and found instant removal at the initial concentration of the adsorbate. Adsorption of metals by activated carbon has been found to be dependent on $\mathrm{pH}$, activated carbon dose and initial metal concentration. Most of the metals are adsorbed in acidic $\mathrm{pH}$ range by activated carbon [Dubinin . 1966].

In single component system, linear adsorption isotherm is observed for cadmium as compared to chromium and lead indicating uniform adsorption throughout the system
In two component system the pattern of adsorption for lead and chromium is found to be similar, for chromium and cadmium linear adsorption is found for cadmium while more and linear adsorption is found in both the case of cadmium and lead in combination. In three-component system, linear adsorption pattern was observed for cadmium in presence of chromium and lead while similar adsorption pattern was observed for chromium in presence of cadmium and lead and lead in presence of cadmium and chromium.

The overall preferential adsorption pattern in multicomponent system of heavy metals was observed to be as $\mathrm{cd}>$ $\mathrm{pb}>\mathrm{cr}$. Generally in wastewater treatment system heavy metals are removed through adsorption in tertiary treatment. So this trend will be useful in removing maximum percentage of heavy metals preferably in multicomponent system.

\section{References}

APHA (1995). Standard methods for the examination of water and wastewater 16th edition, American Public Health Association

Baes G. B. Jr: Mesmer R. W. (1976). Hydrolysis of cations, wiley, New York.

Dara S. S. (1995). Environmental chemistry and pollution control. (S. Chand and company ltd). pp 176.

Davis T. A., Volesky B. and Mucci A. (2003). A review of the biochemistry of heavy metal biosorption by brown algae. Water Research 37(18): 4311-4330.

Dubinin M. M. (1966). Structure and property of active carbon, chemical, Physical Carbon, 2; 251, P.L. Walker, Journal Ed. (Newyork; Marcel Dekkar, IMC).

Joesten M. D. and schaad L. J. (1974). "Hydrogen Bonding", Marcel Dekkar, New York

Joesten M. D. and Bonsal R. C. (1964). studies in surface chemistry of carbon blacks -II, surface acidity in relation to chemisorb oxygen, carbon black-II, 1, 467. 
Morel F. M. M. and Price N.M (2003). The Biogeochemical Cycles of Trace Metals in the Oceans Science, (300): 944 - 947.

Nagel. K. and Voigt J. (1995). Impaired photosynthesis in a cadmium-tolerant Chlamydomonas mutant strain", Microbiol Research, 1995(150), pp. 105-110
Puri B. R. Singh S. and Mahajan O. P. (1965). Acidic Behaviour of charcoal as a function of oxygen complexes and development of surface acidity on treatment with Nitric acid ,J. Indian chemical society, 42: 427.

Sorg T. S. and Logsdon, (1980). Treatment technology to meet the interim primary drinking water standards for inorganics,pt.5: American Water Works Association Journal, 72: 411-422.

Received : July 06, 2009;

Accepted : October 31, 2010 